\title{
LEPTOMENINGITE E TUMOR DA REGIÃO OPTOQUIASMÁTICA
}

\author{
J. A. Gonçalves da Silva * \\ Sylvio Saraiva ** \\ A. SPINA-França ***
}

As relações de contigüidade entre as cisternas interpeduncular e quiasmática, de um lado, e o seio esfenoidal e orofaringe, do outro, explicam como tumores que invadem ou destroem o estojo ósseo craniano podem acompanhar-se de surtos de meningite. A destruição das estruturas que se interpõem entre o espaço subaracnóideo e as partes altas das vias aéreas respiratórias estabelece porta de entrada para os germes habitualmente encontrados nestas últimas, propiciando a ocorrência de infecção leptomeníngea 3,5 .

Como muitos dos tumores que costumam desenvolver-se nessa região são de crescimento lento e só tardiamente determinam sintomatologia que permita orientação diagnóstica adequada, compreende-se porque em muitas ocasiões o quadro clínico se inicie por manifestações meningíticas. Assim sendo, os tumores que invadem o assoalho do andar médio do crânio devem ser excluidos mediante estudos complementares quando se procura elucidar a etiopatogenia de certas leptomeningites, principalmente as que evoluem de modo subagudo apresentando períodos de exacerbação e as meningites agudas recidivantes ${ }^{1}$.

O registro dos casos seguintes se justifica por exemplificar quadros meningíticos associados a tumores dessa região.

\section{OBSERVACOES}

CASo 1 - D.S.H. (Reg. HC 698.930), atendido na Clínica Neurológica a partir de junho, 1963. Paciente branco, do sexo masculino, com 48 anos de idade que, há cêrca de dois anos, vinha apresentando episódios de cefaléia frontal. Ültimamente êsses episódios ocorriam diàriamente e acompanhavam-se, por vêzes, de vômitos não precedidos de náuseas; ao mesmo tempo o paciente passou a emagrecer. Exame clínico-neurológico - Paciente afebril; nada de especial foi verificado no exame geral e o exame neurológico evidenciava apenas discreta rigidez de nuca. O exame do líquido cefalorraqueano (LCR) mostrou pleocitose predominantemente linfomononuclear e hiperproteinorraquia. O paciente foi internado e como nāo melhorasse com a antibioticoterapia foram feitos vários exames para elucidação diagnóstica. Hemograma: 7.600 leucócitos por $\mathrm{mm}^{3}$ (neutrófilos bastonetes $12 \%$, neu-

Trabalho da Clínica Neurológica da Faculdade de Medicina da Universidade de São Paulo (Prof. Adherbal Tolosa): * Médico-estagiário; ** Médico-assistente; *** Professor-assistente. 
trófilos segmentados $43 \%$, eosinófilos $9 \%$, basófilos $2 \%$, linfócitos $30 \%$, monócitos 4\%). Hemossedimentação: $47 \mathrm{~mm}$ na primeira hora. Radiografia do tórax: normal. Radiografia do crânio: desmineralização da tábua óssea ao nivel da sela turca. Carótido-angiografia esquerda: desvio da artéria cerebral anterior para 0 lado direito. Eletrencefalograma: tracado anormalmente lento mostrando predominio de ondas teta, sem anormalidades focais.

Vários exames do LCR feitos durante a internação mostraram a persistência das alterações inicialmente encontradas. A intensidade e o tipo da pleocitose eram variáveis de um para outro exame, ocorrendo polinucleares neutrófilos embora predominassem sempre os linfomononucleares (quadro 1). Os exames bacteriológicos feitos com várias das amostras de LCR nāo evidenciaram o agente etiológicon.

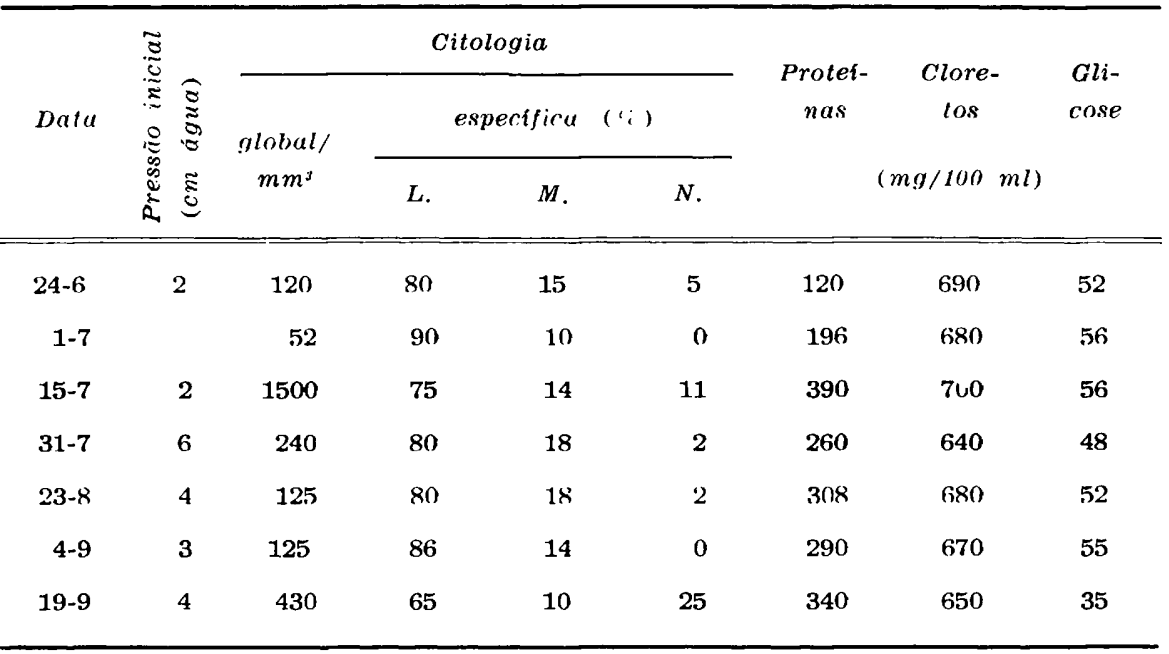

Quadro $t$ - Caso D.S.H. Exames de líquido cefalorraqueano. As amostras de LCR de 24-6 e de 1-7 foram colhidas por puncão lombar $e$ as demais por punç̃o suboccipital. As reações de fixação do complemento para sifilis e para cisticercose foram negativas em várias das amostras examinadas; os exames bacteriológicos (direto e culturas) feitos em várias das amostras também resultaram negativos.

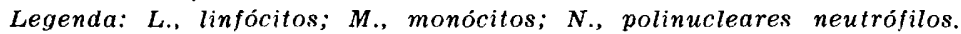

Em vista do achado do craniograma foi feito exame da orofaringe, tendo sido verificado rebaixamento da mucosa. Ao ser submetido à medicação pré-anestésica para biopsia o paciente teve depressão respiratória profunda que impossibilitou o exame. Houve piora progressiva do estado geral do paciente que finalmente entrou em coma, vindo a falecer em outubro de 1963.

Exame necroscópico (SS 66.547/63) - Leptomeningite crônica inespecifica e massa tumoral na região hipofisária que invadia o corpo do esfenóide e a nasofaringe e comprimia a ponte e o bulbo. o exame histopatológico da tumoração mostrou tratar de carcinoma sólido da hipófise (Dr. K. Iriya).

CASo 2 - I.S. (Reg. HC 658.018), atendido na Clinica Neurológica a partir de abril de 1962. Paciente branco, do sexo masculino, com 26 anos de idade, que se queixava de crises de cefaléia intensa e difusa, com duraçāo de dois a três dias, ocorrendo cada 15-20 dias, há cêrca de 8 meses. As crises de cefaléia não cediam com analgésicos e eram acompanhadas de vômitos em jato. Nos últimos meses houve diminuiçāo progressiva da acuidade visual. Anteriormente (novembro de 1961) 
o paciente fôra internado em outro hospital, sendo feito o diagnóstico de meningite, que regrediu com tratamento por antibióticos, tendo tido alta em boas condiçōes. Exame clinico-neurológico - Paciente febril $\left(37,5^{\circ}\right)$, sem alterações aos exames físico e neurológico. O exame do $L C R$ mostrou pleocitose intensa, predominantemente a polinucleares neutrófilos e hiperproteinorraquia. o paciente foi internado e como não melhorasse com a antibioticoterapia, foi submetido a vários exames para elucidação diagnóstica. Hemograma: leucócitos 6.100 por $\mathrm{mm}^{3}$ (neutrófilos bastonetes $8 \%$, neutrófilos segmentados $51 \%$, eosinófilos $6 \%$, linfócitos $25 \%$, monócitos 10\%). Hemossedimentação: $4 \mathrm{~mm}$ na primeira hora. Exame bacterioscópico e micológico do escarro negativo. Cutirreação de Mantoux negativa. Radiografia do tórax normal. Carótido-angiografia esquerda: sinais indiretos de dilatação ventricular. Pneumencefalografia: Imagem lacunar na face orbitária do corno frontal do ventrículo lateral esquerdo. Eletrencefalograma: pequena desorganização da atividade elétrica, nas áreas frontotemporais, por ondas teta, irregulares e de média voltagem. Exame neurocular: fundos oculares normais, retração concêntrica dos campos visuais.

Durante a internação o paciente apresentou diversos episódios de cefaléia, associados a hipertermia que oscilava de 37 a $40^{\circ} \mathrm{C}$. Houve queda progressiva do seu estado geral, entrando finalmente em coma e vindo a falecer em dezembro de 1962.

Vários exames de LCR feitos durante a internação mostraram a persistência das alterações observadas no primeiro exame. A intensidade da pleocitose e da hiperproteinorraquia variavam de um para outro exame. A fórmula citológica também se apresentava variável, predominando por vêzes os linfomononucleares, embora polinucleares neutrófilos fôssem encontrados em todos os exames. Hipoglicorraquia tornou-se evidente nos últimos exames (quadro 2). Diversos exames bacteriológicos do LCR não permitiram encontrar o agente etiológico.

\begin{tabular}{|c|c|c|c|c|c|c|c|c|}
\hline \multirow{3}{*}{ Data } & \multirow{3}{*}{ 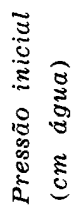 } & \multirow{3}{*}{$\begin{array}{c}\text { global/ } \\
m m^{3}\end{array}$} & \multicolumn{2}{|c|}{ Citologia } & \multirow[b]{2}{*}{$(\%)$} & \multirow{3}{*}{$\begin{array}{c}\text { Protei- } \\
\text { nas }\end{array}$} & \multirow{3}{*}{$\begin{array}{c}\text { Clore- } \\
\text { tos } \\
(m g / 100 \mathrm{ml})\end{array}$} & \multirow{3}{*}{$\begin{array}{l}\text { Gli- } \\
\text { cose }\end{array}$} \\
\hline & & & & fica & & & & \\
\hline & & & $L$ & $M$. & $N$ & & & \\
\hline $11-4$ & & 480 & 20 & 8 & 72 & 280 & 700 & 53 \\
\hline 25- 4 & 5 & 325 & 72 & 22 & 6 & 340 & 700 & 50 \\
\hline $16-5$ & 25 & 1000 & 5 & 5 & 90 & 630 & 700 & 35 \\
\hline 4- 7 & 7 & 200 & 3 & 8 & 89 & 1700 & 720 & 31 \\
\hline $6-8$ & 3 & 1280 & 20 & 8 & 72 & 650 & 700 & 67 \\
\hline $16-8$ & 3 & 165 & 55 & 10 & 35 & 250 & 690 & 53 \\
\hline $20-8$ & 6 & 1280 & 40 & 15 & 45 & 830 & 650 & 48 \\
\hline 21- 9 & & 250 & 80 & 15 & 5 & 2500 & 690 & 43 \\
\hline $22-10$ & & 1730 & 34 & 18 & 48 & 440 & 650 & 44 \\
\hline $23-11$ & 6 & 533 & 5 & 5 & 90 & 920 & 550 & 42 \\
\hline $30-11$ & & 1970 & 93 & 0 & 7 & 1100 & & 44 \\
\hline $19-12$ & & 654 & 20 & 12 & 68 & 310 & 690 & 21 \\
\hline
\end{tabular}

Quadro 2 - Caso I.S. Exames de liquido cefalorraqueano. A amostra de LCR de 21-9 foi colhida por punçio lombar e as demais por puncũo suboccipital. As reacões de fixação do complemento para sifilis e para cisticercose foram negativas em várias das amostras examinadas; os exames bacteriológicos (direto e culturas) feitos em várias das amostras também resultaram negativos. Legenda: L., linfócitos; M., monócitos; N., polinucleares neutrófilos. 
Exame necroscópico (SS 63.112/62) - Leptomeningite, dilatação do sistema ventricular, edema cerebral e tumoração mediana no assoalho do andar médio do crânio, estendendo-se desde o nivel da cisterna interpeduncular até o do terceiro ventriculo. O exame histopatológico do tumor mostrou tratar-se de craniofaringeoma (Dr. O. A. Behmer).

\section{COMENTARIOS}

Nos dois casos a sintomatologia orientou inicialmente o diagnóstico no sentido de processos que causavam irritação meníngea, a qual foi confirmada pelo exame do LCR. O fato de não ter sido encontrado o agente etiológico responsável pelo quadro meningítico nos dois casos, aliado ao insucesso da antibioticoterapia e à evolução subcrônica no primeiro caso e, no segundo, a repetidos surtos de reagudização, levaram à procura de foco intracraniano responsável pela manutenção do processo infeccioso. Os resultados do craniograma e da carótido-angiografia no primeiro caso e, no segundo, da pneumencefalografia e da campimetria visual orientaram para o diagnóstico de processo tumoral no assoalho do andar médio do crânio. Apesar da antibioticoterapia e demais medidas terapêuticas adotadas, não foi possivel obter melhoria do quadro meningítico nem do estado geral dos pacientes, impedindo que em ambos fôssem adotadas, em tempo hábil, medidas terapêuticas diretamente orientadas em relação a êsses focos. Ambos os pacientes vieram a falecer e o exame necroscópico mostrou, ao lado de reação leptomeningítica inespecífica, processo neoplásico situado no assoalho do andar médio: carcinoma sólido da hipófise no primeiro e, no segundo caso, craniofaringeoma.

A origem embrionária dá ao craniofaringeoma papel de relêvo na gênese de pertuitos orofaringo-subaracnóideos que, pelas suas reduzidas dimensões, podem passar despercebidos ao exame radiográfico do crânio. No segundo caso, o carcinoma da hipófise invadia o corpo do esfenóide e fazia saliência ao nivel da orofaringe, podendo ser o responsável pela comunicação entre o meio exterior e o espaço subaracnóideo. Nos dois casos, portanto, os tumores apresentavam condiçōes suficientes para explicar a origem da porta de entrada que da orofaringe deu acesso ao espaço subaracnóideo ao nível das cisternas quiasmática e interpeduncular.

Os tumores intracranianos, especialmente quando invadem o espaço subaracnóideo ou as cavidades ventriculares podem determinar alterações na composição do LCR. A dissociação proteíno-citológica é o achado mais comum nesses casos. Independentemente da ocorrência de cẻlulas tumorais no LCR, pode haver também pleocitose. Esta em geral é discreta e predominantemente a linfomononucleares ${ }^{2,4}$ sendo explicada, em geral, por reação leptomeningea asséptica desencadeada por metabólitos oriundos das células neoplásicas. Ocasionalmente, a pleocitose pode ser intensa, podendo os polinucleares neutrófilos constituir a maioria dos elementos celulares. Nesses casos configura-se um quadro liquórico muito mais próprio ao das meningites sépticas, podendo motivar dúvidas diagnósticas. Estas são comuns nos tumores que se localizam no assoalho do andar médio, em relação aos quais são mais freqüentes as meningites sépticas secundárias. Muitas 
vêzes, nestas últimas, o foco inflamatório séptico leptomeningeo pode encistar-se ao nível das cisternas adjacentes ao tumor, não se isolando o agente etiológico a partir de amostras de LCR colhidas de outras regiões do espaço subaracnóideo. Nos dois casos apresentados, ambas as hipóteses não podem ser excluídas. A favor da natureza séptica do processo alinham-se a intensidade das alterações meningiticas do LCR e os repetidos surtos de piora. Por outro lado, a ausência, no exame necroscópico, de foco inflamatório - cístico ou encistado - ao nivel do tumor e das leptomeninges circunvizinhas é elemento sugestivo do caráter asséptico do processo, apesar da intensidade das alteraçōes do LCR.

\section{RESUMO}

São registrados dois casos de tumores situados no assoalho da fossa craniana média (carcinoma sólido da hipófise e craniofaringeoma) acompanhados de leptomeningite de etiologia não determinada. Especialmente no segundo caso esta se caracterizava pela ocorrência de repetidos surtos de exacerbação. Em ambos o diagnóstico inicial foi de leptomeningite, tendo sido o insucesso das medidas terapêuticas adotadas que levou a estudos radiológicos, na tentativa de evidenciar focos que pudessem estar mantendo a infecção. Em ambos os casos o exame radiológico forneceu dados que permitiram orientar o diagnóstico de tumor do assoalho da fossa craniana média. As condições clínicas, no entanto, impediram que fôssem adotadas em tempo útil medidas terapêuticas que visassem diretamente o tumor, vindo os pacientes a falecer.

A possibilidade da ocorrência de meningites em tumores dessa regiāo é discutida, bem como a natureza séptica ou asséptica da reação inflamatória.

Os casos apresentados permitem concluir que, em processos meningiti$\cos$ de evolução longa, acompanhados de surtos de agudização, nos quais nem mesmo durante os surtos agudos é encontrado o agente etiológico no LCR, a possibilidade da ocorrência de tumores do assoalho da fossa média do crânio deve ser estudada. O estudo deve ser feito precocemente, para permitir a adoção de medidas terapêuticas adequadas, visando diretamente o tumor, em tempo hábil, na tentativa de evitar que os surtos meningíticos venham a comprometer a vida do paciente.

\section{SUMMARY}

Meningitis and tumor of the opto-chiasmatic region. Report of two cases

A study was made of a patient with carcinoma of the hypophisis which invaded the sphenoid bone and made protrusion under the nasopharyngeal mucosa, and that of a patient with craniopharyngeoma. The patients had no symptoms proper to the tumors but presented several episodes of me- 
ningitis. The presence of the tumor, in both cases, was evidenced lately, when the failure of the antibiotic therapy became patent leading to the search of intracranial focuses of infection through radiologic examinations.

The nature of the leptomeningitic episodes is discussed. Their relation to possible communications between the oropharyngeal cavity and the subarachnoid space, secundary to the changes in the anatomic structures of the region provoked by the tumors, is emphasized since these communications make possible the invasion of the subarachnoid space by bacteria. Although this opinion is acceptable in respect to the cases related, it is not possible to exclude the aseptic nature of meningitic episodes observed as no pathogenic micro-organism was isolated from the CSF samples studied and the necroscopic examination showed no septation in the leptomeningeal structures that surrounded the tumor or no obvious focus of infection related to them. Considering the cases reported the authors point out that radiologic and neuro-radiologic examinations must be indicated, as soon as possible, in order to exclude such tumors in patients suffering from meningitis of obscure origin, specially when its course is delayed and/or marked by acute episodes or re-exacerbation.

\section{REFERENCIAS}

1. BOE, J. \& HUSEKLEPP, H. - Recurrent attacks of bacterial meningitis. A "new" clinical problem. Report of five cases. Amer. J. Med. 29:465-475, 1960.

2. FISHER, P. A. - Meningitische Syndrome bei Hirntumoren. Nervenarzt 29: 296-303, 1958.

3. LANGE, O. - O Líquido Céfalo Raquidiano em Clínica. Cia Melhoramentos de São Paulo, São Paulo, 1937, págs. 116-122, 138-157.

4. MARSH, J. S. - Pleocytosis of cerebrospinal fluid (sympathetic meningitis) in tumors of the brain. Report of a case. Bull. Los Angeles Neurol. Soc. 24: $23-26,1959$.

5. MERRITT, H. H. \& FREMONT-SMITH, F. - The Cerebrospinal Fluid. W. B. Saunders Co., Philadelphia, 1937, págs. 150-162.

Clinica Neurológica - Faculdade de Medicina da Universidade de Stio Paulo Caixa Postal 3461 - Sĭo Paulo, sP - Brasil. 